Case Report

\section{A remote cause of anuria in a child}

\author{
Mehtap Çelakıl*, Zelal Ekinci and Kürşat Demir Yıldız \\ Department of Pediatric Nephrology, Faculty of Medicine, Kocaeli University, Kocaeli, Turkey
}

\section{Abstract}

Acute renal injury is a rare complication of idiopathic nephrotic syndrome with mesPGN. Here we present a 2-year-old male patient with 4 days history of anuria, generalized edema and hypervolemia. Any evidence other than proteinuria and renal failure could not be identified with laboratory tests and doppler ultrasonography. Anuric presentation was thought to be related with rapidly progressive glomerulonephritis, diffuse mesangial sclerosis or acute tubular necrosis. However, renal biopsy revealed mesangial proliferative glomerulonephritis (mesPGN). Prednisolone $2 \mathrm{mg} / \mathrm{kg} /$ day was prescribed. Diuresis was started gradually and on the $10^{\text {th }}$ day of disease, anuria was resolved and acute renal injury recovered without any sequel. This case is presented because of the incompatibility between clinical findings and histopathologic diagnosis. It is concluded that although rare, anuria and acute renal injury could be the presenting symptom of idiopathic nephrotic syndrome in childhood.

\section{Introduction}

Acute renal injury together with anuria is an exceptional and worrying complication of idiopathic nephrotic syndrome in childhood [1]. Renal failure may develop rarely in the absence of glomerular inflammation and may occur either at the time of presentation. Evaluation should be performed to exclude severe intravascular volume depletion, acute tubular necrosis, bilateral renal vein thrombosis, acute pyelonephritis and acute interstitial nephritis [2-4]. Here we present a case of mesPGN which presented with anuria and renal injury. We found the case interesting because of the incompatibility between clinical findings and histopathologic diagnosis. The common symptoms associated with mesangial proliferation (mesPGN) did not occur in this patient.

\section{Case summary}

A 2-year-old male patient presented with 4 days history of anuria and generalized edema. There was no medical history such as infections, dehydration, toxic substances or using drugs. The parents were not consanguineous. His weight was $20 \mathrm{~kg}(>97 \mathrm{p}$ ) and his height was $102 \mathrm{~cm}(>97 \mathrm{p}$ ). Vital signs were as follows: a blood pressure of 90/60 $\mathrm{mmHg}(90 \mathrm{p}$ ), a pulse rate of $86 / \mathrm{min}$, a respiratory rate of $22 / \mathrm{min}$ and a body temperature of $36.5^{\circ} \mathrm{C}$. Physical examination was normal except for the generalized edema. Laboratory investigations were as follows: a white blood cell count of (WBC) 10,800 $/ \mathrm{mm} 3$, a hemoglobin level of $10.5 \mathrm{gr} / \mathrm{dl}$, a platelet count of $176,000 / \mathrm{mm} 3$, a blood urea nitrogen level of $77 \mathrm{mg} / \mathrm{dl}$, a serum creatinine level of $3.27 \mathrm{mg} / \mathrm{dl}$, a serum calcium level of $8.5 \mathrm{mg} / \mathrm{dl}$, a serum sodium level of $139 \mathrm{meq} / \mathrm{L}$, a serum

\section{More Information}

*Address for Correspondence: Mehtap Celakil, Department of Pediatric Nephrology, Faculty of Medicine, Kocaeli University, Turkey,

Tel: +905075620063;

Email: mehtapcelakil@yahoo.com

Submitted: 03 February 2020

Approved: 20 February 2020

Published: 26 February 2020

How to cite this article: Çelakıl M, Ekinci Z, YıldıZ $\mathrm{KD}$. A remote cause of anuria in a child. J Clini Nephrol. 2020; 4: 011-013.

DOI: 10.29328/journal.jen.1001050

ORCiD: orcid.org/0000-0002-5354-1455

Copyright: @ 2020 Çelakıl M, et al. This is an open access article distributed under the Creative Commons Attribution License, which permits unrestricted use, distribution, and reproduction in any medium, provided the original work is properly cited.

Keywords: Acute renal injury; Anuria; Infant; mesPGN

Check for updates

OPEN ACCESS

potassium level of $4.5 \mathrm{meq} / \mathrm{L}$, a serum uric acid level of $9.5 \mathrm{mg} / \mathrm{dl}$, a serum albumin level of $2.8 \mathrm{~g} / \mathrm{dl}$, a serum total protein level of $5 \mathrm{~g} / \mathrm{dl}$, a serum phosphorus level of $7 \mathrm{mg} / \mathrm{dl}$, a serum cholesterol level of $137 \mathrm{mg} / \mathrm{dl}$ and a serum triglyceride level of $133 \mathrm{mg} / \mathrm{dl}$. Blood pH was $7.41, \mathrm{HCO}_{3}$ was $23 \mathrm{mEq} / \mathrm{L}$, reticulocyte count was $1.4 \%$ (0.39-7.54), haptoglobin level was 189 (> 30mg/dl), serum complement C3 level was 97 $\mathrm{mg} / \mathrm{dl}$ (90-180) and serum complement C4 level was 24 $\mathrm{mgr} / \mathrm{dl}$ (10-40). ASO level was 29I U/ml. Estimated GFR (calculated by Schwartz formula) was $34 \mathrm{ml} / \mathrm{min} / 1.73 \mathrm{~m}^{2}$ and urine volume was $2 \mathrm{cc} /$ day. Urinalysis showed PH 6.5, density 1045, protein $4+$, blood negative, microscopy 3 RBC and $4 \mathrm{WBC} /$ high power field. Urine protein/creatinine ratio was $30 \mathrm{mg} / \mathrm{mg}$. Serum creatinine was increased up to 5.03 $\mathrm{mg} / \mathrm{dl}$. Renal sonogram and doppler were normal. There was no response to adequate hydration and IV furosemide. He was totally anuric and hemodialysis was performed for every other day because of severe hypervolemia. Following clinical and laboratory evaluation, any evidence other than proteinuria and renal failure could not be identified. Anuric presentation was thought to be related with acute tubular necrosis, diffuse mesangial sclerosis or rapidly progressive glomerulonephritis. Therefore renal biopsy was performed on the 5th day of anuria. Renal biopsy revealed 38 glomeruli. Contradictory to clinical presentation many of the glomeruli seemed normal and normocellular at first glance with 
hematoxylin and eosin. Tubules, interstitial and vascular structures were also normal (Figure 1). Mesangial proliferation was more conspicuous when Periodic Acid Schift staining was performed (Figure 2). Immunofluorescence microscopy revealed mesangial deposits of IgM. The histopathologic diagnosis was mesangial proliferative glomerulonephritis (mesPGN).

After the histopathologic diagnosis was obtained on the $7^{\text {th }}$ day, prednisolone $2 \mathrm{mg} / \mathrm{kg} /$ day was prescribed. Diuresis was started gradually and on the $10^{\text {th }}$ day of disease, anuria was resolved and acute renal injury recovered without any sequel. Remission was held at the $10^{\text {th }}$ day of steroid therapy.

\section{Discussion}

Acute renal injury and anuria is a rare clinic presentation of idiopathic nephrotic syndrome with mesPGN in childhood. Pstrusinka, et al. [5] noticed acute renal injury in 8 of 1006 children (0.8\%) with idiopathic nephrotic syndrome between ages 6 - 17.5. Significant hypoalbuminemia, infection and a severe course of the nephrotic syndrome were reported to be the risk factors for the development of acute renal injury. Bohman, et al. [6] showed a close relationship between the degree of foot process fusion and both GFR and filtration fraction, suggesting that fusion of foot processes could lead to a reduction of glomerular filtering area and/or of permeability to water and small solutes. This reduction is transitory, with

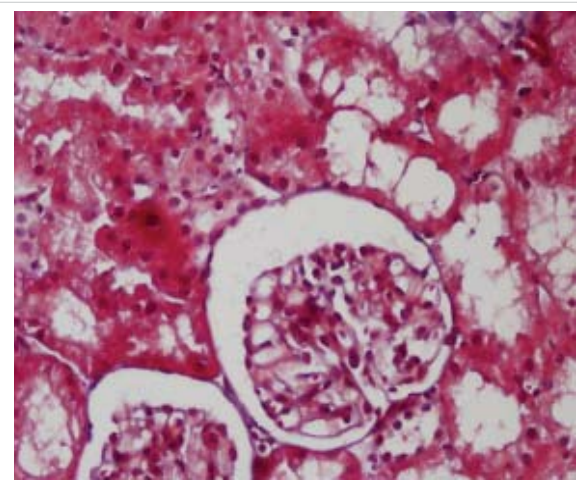

Figure 1: Tubules, glomeruli, interstitial and vascular structures were normal. (Hematoxylin and eosin $\times 100$ ).

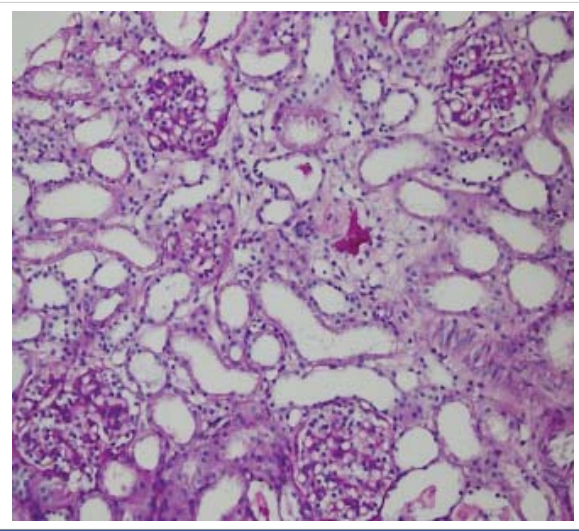

Figure 2: Mesangial proliferation was more conspicuous. (Periodic Acid Schiff staining $\times 100$ ). a rapid return to normal after remission. Van de Walle, et al. [7] found that changes in glomerular permeability may have a major role in acute renal failure. Furthermore mesPGN is a rare form in idiopathic nephrotic syndrome. Mubarak, et al. [8] reported the incidence of mesPGN as $4.81 \%$ and Gulati, et al. [9] as $7.6 \%$ in children. MesPGN is characterized by the proliferation of mesangial cells with an increase in the mesangial matrix and deposits in the mesangial region. Males are 2.5 times more likely to be affected than females [10]. Usually patients with mesPGN present with clinical findings of nephrotic syndrome like edema, hypoalbuminemia, proteinuria and hypercholesterolemia [3]. The normal cholesterol level, together with the slightly decreased albumin level in our patient gave the impression that proteinuria would not be long-lasting. This patient was deemed an interesting case because of the incompatibility between clinical findings and histopathologic diagnosis. Even though he presented with anuria, the final diagnosis was idiopathic nephrotic syndrome with MesPGN. With the history of the patient and findings of renal histopathology, we decided that the severe and sudden course of mesangial proliferation was the cause of anuria in our patient. Treatment was aimed at correcting both the nephrotic syndrome and the renal injury. Corticosteroids are generally the main stay of therapy and rapid recovery is an expected result [10].

\section{Conclusion}

MesPGN is a rare form of idiopathic nephrotic syndrome in children. Anuria and acute renal injury are rare signs as well. On this occasion differential diagnosis should be performed with renal biopsy. Corticosteroid therapy should be the first choice of treatment of mesPGN with acute renal injury for clinical improvement.

\section{References}

1. Agarwal N, Phadke KD, Garg I, Alexander P. Acute renal failure in children with idiopathic nephrotic syndrome. Pediatr Nephrol. 2003; 18:1289-1292.

PubMed: https://www.ncbi.nlm.nih.gov/pubmed/14579139

2. Sakarcan A, Timmons C, Seikaly M. Reversible idiopathic acute renal failure in children with primary nephrotic syndrome. J Pediatr. 1994: 125: 723-727.

PubMed: https://www.ncbi.nlm.nih.gov/pubmed/7965423

3. Smith JD, Hayslett JP. Reversible renal failure in nephrotic syndrome. Am J Kidney Dis. 1992; 19: 201-213.

PubMed: https://www.ncbi.nlm.nih.gov/pubmed/1553965

4. Ahmed M. Minimal Change Nephrotic Syndrome Presenting as Acute Renal Failure. Indian Pediatr. 2003; 40: 676-678. PubMed: https://www.ncbi.nlm.nih.gov/pubmed/12881627

5. Pstrusinska $K$, Zwolinska D, Musial K. Acute renal failure in children with idiopathic nephrotic syndrome. Pol Merkuriusz Lek 2000; 8:462-464.

6. Bohman SO, Jaremko G, Bohlin AB, Berg U. Foot process fusion and glomerular filtration rate in minimal change nephrotic syndrome. Kidney Int. 1994; 25: 696-700.

PubMed: https://www.ncbi.nlm.nih.gov/pubmed/6482174

7. Vande Walle J, Mauel R, Raes A, Vandekerckhove K, Donckerwolcke. 
ARF in children with minimal change nephrotic syndrome may be related to functional changes of the glomerular basal membrane. Am J Kidney Dis. 2004; 43: 399-404.

PubMed: https://www.ncbi.nlm.nih.gov/pubmed/14981597

8. Mubarak M, Lanewala A, Kazi IJ, Akhter F, Sher A, et al. Histopathological spectrum of childhood nephrotic syndrome in Pakistan. Clin Exp Nephrol. 2009; 13: 589-593.

PubMed: https://www.ncbi.nlm.nih.gov/pubmed/19636666
9. Gulati S, Sharma PA, Sharma RK, Gupta A, Gupta RK. Do current recommendations for kidney biopsy in nephrotic syndrome need modifications? Pediatr Nephrol. 2002; 17: 404-408.

PubMed: https://www.ncbi.nlm.nih.gov/pubmed/12107803

10. Sinha A, Bagga A. Nephrotic Syndrome. Indian J Pediatr. 2012; 79: 1045-1055.

PubMed: https://www.ncbi.nlm.nih.gov/pubmed/22644544 